\title{
Evaluation of Allowable Bending Stress of Dimension Lumber; Confidence Levels and Size-adjustment ${ }^{* 1}$
}

\author{
Sung-Jun Pang*2, Jun-Jae Lee ${ }^{* 3 \dagger}$, and Jung-Kwon $\mathrm{Oh}^{* 3 \dagger \dagger}$
}

\begin{abstract}
The aim of this study was to investigate the processes for evaluating the allowable bending stress. The confidence levels and the size-adjustment in standards were reviewed with experimental data. The results show that, (1) KS F 2152 was more strict than others overseas standards due to the higher confidence level. The 5\% NTL of bending strengths by a method in KS F 2152 were lower than the overseas standards and more specimens were required for evaluating the structural properties according to KS F 2152 . (2) Due to the absence of size-adjustment method in domestic standards, the specified size and the exponential parameters on the size-adjustment equation were reviewed by size factors. The specified size (width: $286 \mathrm{~mm}$, length: $6096 \mathrm{~mm}$ ), and the exponential parameters ( $w: 0.29, l: 0.14)$ will be suitable for developing the allowable bending stress in domestic standard. (3) The size adjusted allowable bending stresses of No. 2 grade Korean pine were lower than the allowable stresses tabulated in KBC even though less strict method $(75 \%$ confidence level) to calculate $5 \%$ value was used. The allowable stresses tabulated in $\mathrm{KBC}$ are needed to be reviewed by continuous experimental data.
\end{abstract}

Keywords : confidence level, size-adjustment, lumber, allowable bending strength, size factor

\section{INTRODUCTION}

The processes of developing allowable properties for visually graded lumber were specified in the Korean Standards (KS). KS F 2152 provides a method for establishing allowable properties for softwood structural lumber. Some of the necessary calculations are clearly specified in this standard; however, in some cases, the standard merely indicates the need to make an adjustment, and does not specify how to do so. For user convenience and to reduce mistakes in calculation, the standard needs to be more clearly described. This study discusses how to evaluate the allowable properties, comparing KS F 2152 with overseas standards.

Allowable strength properties are calculated by estimating a lower- $5^{\text {th }}$ percentile of a pop-

*1 Received on June 13, 2013; accepted on September 17, 2013

*2 Department of Forest Sciences, College of Agriculture \& Life Sciences, Seoul National University, Seoul 151-742, Korea

*3 Department of Forest Sciences, Research Institute for Agriculture and Life Sciences, College of Agriculture \& Life Sciences, Seoul National University, Seoul 151-742, Korea

† Corresponding author : Jun-Jae Lee (e-mail: junjae@snu.ac.kr)

†† Co-Corresponding author : Jung-Kwon Oh (e-mail: jkoh75@hotmail.com) 
ulation and then dividing that value by duration of load and safety factors. The lower- $5^{\text {th }}$ percentile is commonly used to describe the strength properties of wood products. Two different methods have been used to characterize the lower- $5^{\text {th }}$ percentile. The first method uses parametric models, in which one of distribution was assumed to estimate $5^{\text {th }}$ percentile, such as normal, lognormal, two-parameter (2-P) Weibull, and three-parameter (3-P) Weibull distributions. The parametric models were used by previous researchers in order to evaluate domestic lumber (Oh et al., 1993; Lee et al., 2003; Park et al., 2010; Lim et al., 2010; Pang et al., 2011). The second method, a non-parametric model, makes no assumptions about the form of the underlying distribution and is based on order-statics. Because the non-parametric model can avoid the error in distribution form assumption, the nonparametric model is preferred (ASTM D1990, 2007). ASTM D 2915 provides tables for determining the associated order-statistics as a function of sample size and significance level (at 75, 95 and $99 \%$ confidence). The choice of a specific confidence is dependent upon the end-use of the material, economic considerations, current design practices, and code requirements. In U.S and Canada, the North American In-grade testing program uses a $75 \%$ confidence level (Evans et al., 2001). International standard (ISO 13910, 2005) and Australian/New Zealand Standard (AS/NZS 4063.2, 2010) also provide statistical processing with a $75 \%$ confidence level. However, KS F 2152 provides statistical processing only with a $95 \%$ confidence level, not $75 \%$ confidence level.

After determining the lower- $5^{\text {th }}$ percentile of a population, the value needs to be adjusted into a specified size. The tabulated allowable bending stresses in Korean Building Code (KBC) apply to $286 \mathrm{~mm}$ width of dimension lumber. For all other sizes of grades, the values should be adjusted by a size factor, $C_{F}$, in KBC. Conver sely, in order to develop allowable properties, a size-adjustment equation must be used to adjust the tested properties to the specified size which are tabulated in building code/standard such as $\mathrm{KBC}$ and NDS. However, no size-adjustment method is described in KS. In order to use the size-adjustment equation, the specified size and the exponential parameters should be determined prior to applying in domestic standard.

As previously mentioned, there are some differences between KS F 2152 and overseas standards. The aim of this study was to investigate the processes for evaluating the allowable bending stress. In particular, the confidence levels and the size-adjustment in standards were reviewed with experimental data.

\section{MATERIALS and METHODS}

\subsection{Materials}

Two commercially important softwood species, Japanese larch (Larix kaempferi Carr., oven- dry density: $\left.540 \mathrm{~kg} / \mathrm{m}^{3}\right)$ and Korean pine (Pinus koraiensis Sieb. et Zucc., oven-dry density: $450 \mathrm{~kg} / \mathrm{m}^{3}$ ) in Gangwon Province were used as specimens. After kiln drying, the surfaces were planed so that the final cross-sections were $38 \times 140 \mathrm{~mm}$ and the lengths were 3,000 $\mathrm{mm}$. The moisture content of the specimens was approximately $15 \%$.

\subsection{Methods}

\subsubsection{Experimental Procedures}

Each specimen was visually graded using the KFRI notification 2009-01. Bending strength measurements were performed using a thirdpoint bending test using a universal testing machine (Zwick GmbH \& Co., Ltd., Ulm, Germany). The length of the test specimens was $3,000 \mathrm{~mm}$ 
and the test span was $2,700 \mathrm{~mm}$. The loading speed was $10 \mathrm{~mm} / \mathrm{min}$. The major defects governing the grade of lumber were randomly distributed in the maximum moment zone.

\subsubsection{Lower $-5^{\text {th }}$ Percentile Strength}

\subsubsection{Nonparametric Point Estimate}

The sample nonparametric $5^{\text {th }}$ percentile point estimate ( $5 \% \mathrm{NPE})$ was interpolated from the samples. The test values were arranged in ascending order. Beginning with the lowest value, $i /(n+1)$ was calculated. The $5 \%$ NPE was interpolated by Eq. (1).

$$
\begin{aligned}
5 \% \mathrm{NPE}= & {\left[\frac{5}{100}(n+1)-(j-1)\right] } \\
& {\left[x_{j}-x_{(j-1)}\right]+x_{(j-1)} }
\end{aligned}
$$

where,

$n$ : total number of samples,

$j$ : the lowest order of the test value when

$$
i /(n+1) \geq 0.05,
$$

$i$ : the order of the test value,

$x_{i}: i$ th value

\subsubsection{Nonparametric Lower Tolerance Limits}

Nonparametric point estimates (NPE) of test samples are calculated to approximate true population percentiles. The estimate from a given sample should accurately represent the true population. In many situations, it is preferable to determine the interval within which one would expect to find the true value of the population. This interval is called an interval estimate. Tolerance limits are a kind of interval estimate, and when obtained using nonparametric procedures, they are called nonparametric lower tolerance limits (NTL) (Barrett et al., 1994).
Table 1. Sample sizes and order statistics for

\begin{tabular}{|c|c|c|c|}
\hline \multicolumn{2}{|c|}{$75 \%$ Confidence } & \multicolumn{2}{|c|}{ 95\% Confidence } \\
\hline $\begin{array}{l}\text { Sample } \\
\text { size }\end{array}$ & $\begin{array}{c}\text { Order } \\
\text { statistic }\end{array}$ & $\begin{array}{l}\text { Sample } \\
\text { size }\end{array}$ & $\begin{array}{c}\text { Order } \\
\text { statistic }\end{array}$ \\
\hline 28 & 1 & 59 & 1 \\
\hline 53 & 2 & 93 & 2 \\
\hline 78 & 3 & 124 & 3 \\
\hline 102 & 4 & 153 & 4 \\
\hline 125 & 5 & 181 & 5 \\
\hline 148 & 6 & 208 & 6 \\
\hline 170 & 7 & 234 & 7 \\
\hline 193 & 8 & 260 & 8 \\
\hline 215 & 9 & 286 & 9 \\
\hline 237 & 10 & 311 & 10 \\
\hline 259 & 11 & 336 & 11 \\
\hline 281 & 12 & 361 & 12 \\
\hline 303 & 13 & 386 & 13 \\
\hline 325 & 14 & 410 & 14 \\
\hline 347 & 15 & 434 & 15 \\
\hline 455 & 20 & 553 & 20 \\
\hline 562 & 25 & 671 & 25 \\
\hline 668 & 30 & 786 & 30 \\
\hline 879 & 40 & 1,013 & 40 \\
\hline 1,089 & 50 & 1,237 & 50 \\
\hline
\end{tabular}
estimating the $5^{\text {th }}$ percentile with $75 \%$ and $95 \%$ confidence

* This table is reproduced from ASTM D2915

The $5^{\text {th }}$ percentile nonparametric lower tolerance limit (the lower-5\% NTL) was determined by an $m^{\text {th }}$ order statistic with the sample size at 75 and $95 \%$ confidence levels, respectively, as shown in Table 1. As the sample size increases, the tolerance limit is more likely to be close to 
the population value. Thus, it is desirable to select as large a sample size as possible after considering the cost of sampling and testing. For sample sizes that fall between the higher and lower sample sizes, interpolation was used to determine the lower-5\% NTL by Eq. (2).

$$
\begin{aligned}
f_{0.05}= & \left(\frac{\text { Sample size }- \text { Lower sample size }}{\text { Higher sample size }- \text { Lower sample size }}\right) \times \\
& \left(f_{\text {above } f_{0.05}}-f_{\text {below } f_{0.05}}\right)+f_{\text {below } f_{0.05}}
\end{aligned}
$$

\subsubsection{Near-minimum Bending Strength}

The value of the near-minimum bending strength was the sample 5\% NPE if the relative difference between the 5\% NPE and the lower $5 \%$ NTL was sufficiently small (that is, if $(5 \%$ NPE - the lower- $5 \%$ NTL) $/ 5 \%$ NPE $<\delta$, where $\delta$ will normally be in the range from 0.01 to $0.10)$. This condition reflected the sufficiently narrow confidence interval for the NPE. When this condition was not satisfied, the lower-5\% NTL was used for the property value. If the latter course is chosen, it is important to be aware of the imprecision of the lower 5\% NTL as a consequence of the sample size (ASTM D 2915, 2010).

\subsubsection{Size-adjustment}

The equation used for adjusting strength properties from the tested size to a specified size is found in ASTM D 1990, Section 8.4.3, and is shown here as Eq. (3).

$$
F_{2}=F_{1}\left(\frac{W_{1}}{W_{2}}\right)^{w}\left(\frac{L_{1}}{L_{2}}\right)^{l}
$$

where,

$F_{l}$ : the bending strength of the tested size,

$F_{2}$ : the bending strength of the specified size,

$W_{1}$ : the width of the tested size, $140 \mathrm{~mm}$

$W_{2}$ : the width of the specified size, $286 \mathrm{~mm}$
$L_{1}$ : the length of the tested size, $2700 \mathrm{~mm}$

$L_{2}$ : the length of the specified size, $6096 \mathrm{~mm}$

$w$ and $l$ : exponential parameter, 0.29 and 0.14 , respectively

\section{RESULTS and DISCUSSION}

\subsection{Lower-5th Percentile Strength}

When a $5 \%$ NPE is used to represent the true $5^{\text {th }}$ percentile of the population, there is a $50 \%$ chance that it lies above or below the true value. On the other hand, if the lower-5\% NTL with a $95 \%$ confidence level is used to estimate the true $5^{\text {th }}$ percentile of the population, there is only a $5 \%$ chance that the true $5^{\text {th }}$ percentile of the population is below the lower-5\% NTL. Thus, the lower- $5 \%$ NTL value is a more conservative estimate of the true population than the $5 \%$ NPE.

In our test results, the lower-5\% NTL strengths of KS F 2152 were lower than the overseas standards (Table 2). The lower-5\% NTL strengths were decided at $95 \%$ confidence in KS F 2152 , $75 \%$ confidence in AS/NZS 4063.2, and the value of near-minimum bending strength in ASTM D 2915. The Korea Standard, KS F 2152 , provides only the lower-5\% NTL at a $95 \%$ confidence level, unlike overseas standards such as ASTM 2915 and AS/NZS 4063.2. Thus, a strength property of lumber evaluated by the KS F 2152 will be resulted in a lower value than by overseas standards.

In the case of the KS F 2152, more specimens are required for evaluating the structural properties of No. 3 grade (Table 2), where the sample sizes were too small to evaluate the lower-5\% NTL at a 95\% confidence level. The strength characteristics can be determined by destructive tests, and the minimum sample size requires 59 test pieces at the $95 \%$ confidence level; however, only 28 test pieces are required 
Sung-Jun Pang, Jun-Jae Lee, and Jung-Kwon Oh

Table 2. Lower- $5^{\text {th }}$ percentile strengths according to various standards

\begin{tabular}{lcccccc}
\hline \multirow{2}{*}{ Species } & \multirow{2}{*}{ Grade } & Sample & \multicolumn{3}{c}{ The selected 5th percentile value } \\
\cline { 6 - 7 } & & Size & & KS F 2152 & AS/NZS 4063.2 & ASTM D2915 \\
\hline \hline \multirow{3}{*}{ Japanese larch } & No.1 & 369 & & 30.5 & 32.2 & 32.7 \\
& No.2 & 111 & & 19.1 & 19.3 & 20.1 \\
& No.3 & 34 & - & 14.0 & 14.0 \\
\hline \multirow{3}{*}{ Korean pine } & No.1 & 116 & 16.6 & 17.8 & 19.7 \\
& No.2 & 104 & 9.4 & 10.2 & 10.2 \\
& No.3 & 35 & - & 8.3 & 9.2 \\
\hline
\end{tabular}

1) $5 \%$ NTL at $95 \%$ confidence

2) $5 \%$ NTL at $75 \%$ confidence

3) Near-minimum bending strength at $75 \%$ confidence

at the $75 \%$ confidence level (Table 1). Thus, evaluating the structural properties at a $75 \%$ confidence level is easier for sampling. In reality, the $5^{\text {th }}$ percentile value at a $75 \%$ confidence level is widely used. In North America, the minimum sample size of 28 is required according to ASTM D 2915. Minimum sample sizes of 40 and 30 for the ISO 13910 and AS/NZS 4063.2, respectively, are required. Thus, KS F 2152 is more strict than others overseas standards when calculating the $5^{\text {th }}$ percentile value.

\subsection{Size Adjustment}

If allowable bending stresses were determined without size adjustment, the resistance of lumber would be over-determined in design. As an example, the tested 5\% NTL for $38 \times 140 \mathrm{~mm}$ No.1 grade of Japanese larch was $30.5 \mathrm{MPa}$ (Table. 2). The allowable bending stress based on this test result would be determined as 14.5 MPa after dividing the tested 5\% NTL by 2.1 for duration of load and safety factor. When designing the strength of $38 \times 140 \mathrm{~mm}$ lumberbased on the tested allowable stress, the resistance of the lumber would be calculated by mul- tiplying size factor, $1.3(\mathrm{KBC})$. As a result, the design strength would be $18.8 \mathrm{MPa}$. It is higher than the actually measured allowable bending stress. If considering 2.1 again which is the load duration and safety factor, it would be 39.4 $\mathrm{MPa}$ and this value is much higher than the actually measured 5\% NTL. Therefore, when determining allowable bending stress, the tested strength should be adjusted into specified size by considering size factors.

Broad experiments have been carried out to make an equation to adjust measured strength into a specific size (Barrett et al., 1995). The size-adjustment equation for developing allowable properties was based on the weakest-link theory and adopted in overseas standards. In the size-adjustment equation, the specified size and exponential parameters are used. There are some different opinions in the exponential parameter and the specified size is different between countries.

In case of National Design Specification (NDS) and Canadian Standards Association (CSA) O86-09, the tabulated size factors were determined at the specified widths and lengths (Table 3) with the size-adjustment equation, Eq. 
Evaluation of Allowable Bending Stress of Dimension Lumber; Confidence Levels and Size-adjustment

Table 3. Size factors for bending strength of dimension lumber (38 64mm thickness) in structural design

\begin{tabular}{|c|c|c|c|c|c|}
\hline \multirow{2}{*}{ Width (mm) } & \multicolumn{2}{|l|}{ NDS } & \multicolumn{2}{|c|}{ CSA O89 } & \multirow{2}{*}{$\frac{\mathrm{KBC}}{C_{F}{ }^{5)}}$} \\
\hline & Length $(\mathrm{mm})^{1)}$ & $C_{F}^{2)}$ & Length $(\mathrm{mm})^{3)}$ & $K_{Z b}^{4)}$ & \\
\hline $38 \sim 89(2,3, \& 4$ in. $)$ & 3658 (144 in.) & 1.5 & 1513 & 1.7 & 1.5 \\
\hline 114 (5 in.) & 3658 (144 in.) & 1.4 & 1938 & 1.5 & 1.4 \\
\hline 140 (6 in.) & 3658 (144 in.) & 1.3 & 2380 & 1.4 & 1.3 \\
\hline 184 (8 in.) & 3658 (144 in.) & 1.2 & 3128 & 1.2 & 1.2 \\
\hline 235 (10 in.) & 4878 (192 in.) & 1.1 & 3995 & 1.1 & 1.1 \\
\hline 286 (12 in.) & 6096 (240 in.) & 1.0 & 4862 & 1.0 & 1.0 \\
\hline over 336 ( 14 in. \& wider) & 6096 (240 in.) & 0.9 & 5729 & 0.9 & 0.9 \\
\hline
\end{tabular}

1) Evans et al., 2001, p.15

2) American Forest \& Paper Association, 2011, p.30

3) Barrett et al., 1994, p.281 (Length $=17 \times$ Width of lumber)

4) CSA O86-09, 2009, p.30

5) Korean Building Code, 2009, p.660

(3). The specified widths were the same between NDS and CSA O86-09 and the specified strengths were based on the widest common lumber size, 12" (286 mm). However, the specified lengths and exponential parameters on size-adjustment equation were different between NDS and CSA O86-09. In case of NDS, the exponential parameters, $w$ and $l$, were 0.29 and 0.14 , respectively, and the specified length for the specified strengths was 240 in. $(6,096 \mathrm{~mm})$ (Evans et al., 2001). In case of CSA O86-09; however, the both exponential parameters were the same as 0.23 and the specified length for the specified strengths was 4,862 mm (Barrett et al., 1994). As a result, the tabulated size factors are different between NDS and CSA O86-09.

The size factors for adjusting the specified strength to all other width were the same at 38 64 mm thicknesses lumber between KBC and NDS (Table 3). The size factor for $38 \times$ $140 \mathrm{~mm}$ is 1.3 at $38 \sim 64 \mathrm{~mm}$ thicknesses in
KBC and NDS. In CSA O86-09, however, the size factor for $38 \times 140 \mathrm{~mm}$ is 1.4 at $38 \sim 64$ $\mathrm{mm}$ thicknesses lumber. It indicates that the size factors in KBC can be derived by the same parameters for NDS. Thus, it is appropriate to apply the specified size (width: $286 \mathrm{~mm}$, length: $6,096 \mathrm{~mm}$ ), and the exponential parameters ( $w$ : $0.29, l: 0.14$ ) for developing the allowable bending stress at 38 64 mm thicknesses lumber in domestic standard.

\subsection{Difference of Allowable Bending Stress Determined by Different Standards}

Three different types of allowable bending stresses were derived from the tested data in order to compare with the allowable bending stres $\mathrm{s}$ tabulated in KBC (Table 4). In case of the values in third column of Table 4 , the lower-5\% NTL at $95 \%$ confidence was divided by 2.1 , which is the reduction factor of bending 
Table 4. Comparisons of allowable bending stresses

\begin{tabular}{lccccc}
\hline \multirow{2}{*}{ Species } & \multirow{2}{*}{ Grade } & \multicolumn{4}{c}{ Allowable bending stresses (MPa) } \\
\cline { 3 - 6 } & & KS F 2152 & Size-adjusted KS F 2152 & ASTM D1990 & KBC $^{4)}$ \\
\hline \hline \multirow{3}{*}{ Japanese larch } & No.1 & 14.5 & 10.5 & 11.1 & 8.0 \\
& No.2 & 9.1 & 6.6 & 6.7 & 6.0 \\
& No.3 & - & - & 4.8 & 3.5 \\
\hline \multirow{3}{*}{ Korean pine } & No.1 & 7.9 & 5.7 & 6.2 & 6.0 \\
& No.2 & 4.5 & 3.2 & 3.5 & 5.0 \\
& No.3 & - & - & 2.9 & 3.0 \\
\hline
\end{tabular}

1) $5 \%$ NTL at $95 \%$ confidence / 2.1

2) size-adjusted $5 \%$ NTL at $95 \%$ confidence / 2.1

3) size-adjusted $5 \%$ NTL at $75 \%$ confidence / 2.1

4) Tabulated design values in Korean Building Code 2009

strength for the duration of load and safety. The size-adjusted values in fourth column of Table 4 were derived from the allowable bending stresses in KS F 2152. The size-adjusted allowable bending stresses are more suitable for comparing with the tabulated allowable bending stresses in $\mathrm{KBC}$, because, as mentioned previously, the tabulated bending stresses in $\mathrm{KBC}$ apply for $286 \mathrm{~mm}$ width lumber. The allowable bending stresses in fifth column of Table 4 were derived by dividing the size-adjusted $5 \%$ NTL at a $75 \%$ confidence by 2.1 . Due to the applied lower confidence level than KS F 2152, the higher allowable bending stresses were derived than the size-adjusted KS F 2152.

The size-adjusted allowable bending stress of No. 2 grade Korean pine were lower than the allowable stresses tabulated in $\mathrm{KBC}$ even though less strict method (75\% confidence level) to calculate $5 \%$ value was used. This indicates that the allowable stresses tabulated in $\mathrm{KBC}$ are needed to be reviewed by continuous experimental data. Due to the limitations of this study, the experiments were only performed with the dimension lumber produced in one re- gion, additional random sampling is necessary in various regions in subsequent research.

\section{CONCLUSIONS}

This study investigated the processes for evaluating the allowable bending stress. The confidence levels and the size-adjustment in standards were reviewed with experimental data.

(1) KS F 2152 was more strict than others overseas standards due to the higher confidence level. The 5\% NTL of bending strengths by a method in KS F 2152 were lower than the overseas standards and more specimens were required for evaluating the structural properties according to KS F 2152.

(2) Due to the absence of size-adjustment method in domestic standards, the parameters in the size-adjustment equation were determined by the size factors. The specified size (width: $286 \mathrm{~mm}$, length: 6,096 mm), and the exponential parameters ( $w: 0.29, l: 0.14)$ will be suitable for developing the allowable bending stress in domestic standard.

(3) The size adjusted allowable bending stress 
of No. 2 grade Korean pine were lower than the allowable stresses tabulated in KBC even though less strict method (75\% confidence level) to calculate $5 \%$ value was used. The allowable stresses tabulated in KBC are needed to be reviewed by continuous experimental data.

\section{ACKNOWLEDGMENT}

This study was carried out with the support of 'Forest Science \& Technology Projects (Project No. S111213L100110)' provided by Korea forest Service.

\section{REFERENCES}

1. American Forest \& Paper Association. 2011. National Design Specification (NDS) for Wood Construction Supplement: Design Values for Wood Construction 2012 Edition.

2. AS/NZS 4063. 2. 2010. Characterization of structural timber part 2: determination of characteristic values.

3. ASTM D1990. 2007. Standard practice for establishing allowable properties for visually-graded dimension lumber from in-grade tests of full-size specimens.

4. ASTM D2915. 2010. Standard practice for sampling and data-analysis for structural wood and wood-based products.

5. Barrett, J. D. and W. Lau. 1994. Canadian lumber properties. Canadian Wood Council.

6. Barrett, J. D., F. Lam, and W. Lau, 1995. Size effects in visually graded softwood structural lumber. Journal of materials in civil engineering 7(1): $19 \sim 30$.

7. CSAO86-09. 2009. Engineering Design in Wood. Canadian Standards Association, Mississauga, Ontario, Canada.

8. Evans, J. W., D. E. Kretschmann, V. L. Herian, and D. W. Green. 2001. Procedures for developing allowable properties for a single species under ASTM D1990 and computer programs useful for the calculations. US Department of Agriculture, Forest Service, Forest Products Laboratory.

9. ISO 13910. 2005. Structural timber - characteristic values of strength-graded timber - sampling, full-size testing and evaluation.

10. Korean Building Code. 2009. Minister of Land, Transport and Maritime Affairs notification 2009 1245.

11. KS F 2152. 2004. Establishing allowable properties of softwood structural lumber.

12. KFRI notification 2009-1. 2009. Softwood structural lumber. Korea Forest Research Institute.

13. Lee, J. J., G. C. Kim, K. M. Kim, and J. K. Oh. 2003. Distribution Characteristics of Bending Properties for Visual Graded Lumber of Japanese Larch. MokchaeKonghak 31(5): 72 79.

14. Lim, J. A., J. K. Oh, H. M. Yeo, and J. J. Lee. 2010. Feasibility of Domestic Yellow Poplar (Liriodendron tulipifera) Dimension Lumber for Structural Uses, MokchaeKonghak 38(6): 470 479.

15. Oh, S. C., M. J. Park, and K. Shim. 1993. Stress Grading of Domestic Softwood $2 \times 4$ Lumber. Journal of Korea Furniture Society 4(1): 8 13.

16. Pang, S. J., J. K. Oh, C. Y. Park, J. S. Park, M. J. Park, and J. J. Lee. 2011. Characteristics Evaluation of Bending Strength Distributions on Revised Korean Visual Grading Rule, Mokchae Konghak 39(1): 1 6.

17. Pang, S. J., J. S. Park, K. H. Hwang, G. Y. Jeong, M. J. Park, and J. J. Lee, 2011. Bending strength of Korean softwood species for $120 \times 180$ mm structural members, J. Korean Wood Sci. \& Tech. 39(5): 444 450.

18. Park, C. Y., S. J. Pang, J. S. Park, K. M. Kim, M. J. Park, and J. J. Lee. 2010. Study of the distribution properties and LRFD code conversion in Japanese larch. MokchaeKonghak 38(2): 94 100. 